\title{
Behaviour of Reactive Powder Concrete In Direct Shear
}

\author{
Mr. M K Maroliya. \\ Assistant professor, Applied Mechanics Dept, Faculty of Technology \& Engineering, M.S. University of Baroda, \\ Vadodara,
}

\begin{abstract}
This paper presents an experimental investigation to focus specifically a structural performance in response to shear loading including failure mode, ultimate strength, first crack load and structural integrity. A series of direct shear specimens having inverted " $L$ " shape in shear failure plane were tested using optimized Reactive powder concrete (RPC) Shear strength test setup is proposed in which preparation of specimens and testing operation can be made the simplest and at the same time ensures reliable and consistent results. The experimental results show that RPC exhibits ductile failure mode, higher ultimate strength in addition to much improved structural integrity.
\end{abstract}

Key Words-RPC, shear strength, first crack load, Ductility.

\section{INTRODUCTION}

The term ultra high-strength concrete generally is used for Reactive Powder Concrete (RPC) with compressive strength higher than $100 \mathrm{MPa}$. But ultra high-strength concrete is considered to be a relatively brittle material because the post-peak portion of its stress-strain diagram descends deeply or almost vanishes as compressive strength increases.

The shear strength of concrete is the resistance of one layer with respect of other during slip at common surface of contact.

A compromise between strength and ductility can be obtained by using discontinuous fibers.. Adding fibers to concrete makes it a homogenous and isotropic material and converts its brittle characteristics to ductile one. When concrete cracks, the randomly oriented fibers function to arrest micro cracking. Thus, improving the first-crack shear strength increased significantly. Improvements in ultimate shear strength. Adding fibers influences the ascending portion of the stress-strain curve only slightly but leads to a noticeable increase in the peak strain and a significant increase in ductility, as described by the area under the descending portion of the curve.

Reinforced concrete beam under bending load maintains its ductility by yielding of the reinforcing steel. However, it soon became clear that such reinforced concrete members can fail in shear, and that shear failure can be catastrophic. A case in point is the punching failure of bridge decks. In addition, shear failure can occur in anchor bolts embedded in concrete, in corbels and in shear keys of segmental bridges. The connection between beam columns and the base of shear walls are also likely to be subjected to intensive shear during earthquake loading.

Shear transfer mechanism in FRC, N.K. Bairagi and C. D. Modhera [12] proposed an experimental set up for finding out shear strength in absence of any standard procedure to measure shear.

\section{LITERATURE REVIEW AND METHODOLOGY}

Different methods used to determine the shear strength using FRC specimens. The shear strength of concrete is the resistance of one layer with respect to other during slip at common surface of contact. There is questioned that two planes failing simultaneously in double shear doesn't happen in reality and hence shear strength calculated in this manner could be said to be erroneous. And there exists no standard reliable and simplified method getting shear strength of concrete specimens using compressive testing machine.

Bairagi and Modhera [12] checked the feasibility and reliability of the test method proposed by them with the test method suggested by JSCE method. Results obtained by their proposed method were $10 \%$ higher than that of JSCE method. They concluded that by comparing the procedure of test methods and fabrication of test assemblies as well as the test specimen, their proposed method is simpler to handle compared to JSCE method.

During the performance of the test using the arrangement as suggested by Bairagi and Modhera, it was seen that the roller penetrates down in the specimen, not giving the correct picture of the failure. Also the results 
reported by them were on higher side compared to that of JSCE method in case of fiber reinforced concrete samples.

Thus it was decided to use a strip of size $150 \times 20 \times 22 \mathrm{~mm}$ as shown in instead of roller keeping all other things the same.

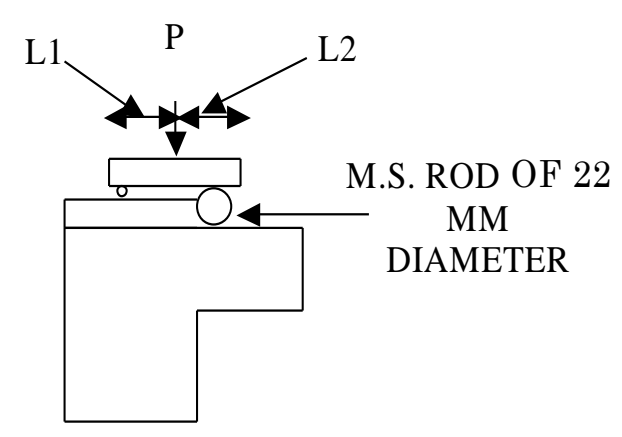

FIG 1.0: TESTING SET-UP SUGGESTED BY BAIRAGI \& MODHERA

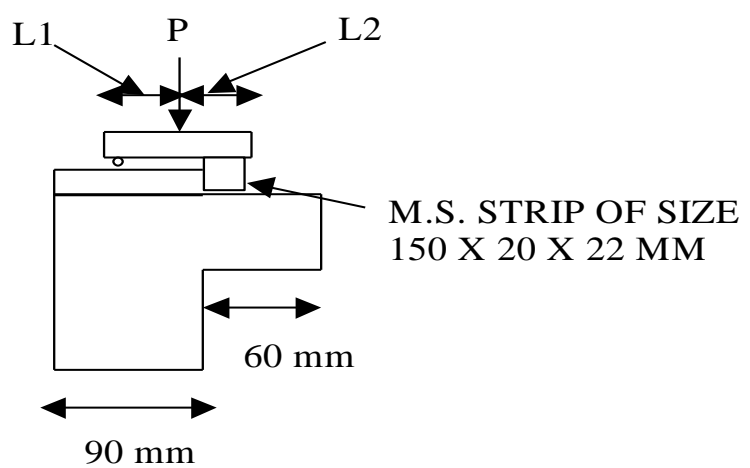

FIG 2.0: TESTING SET-UP FOR SHEAR TEST OF RPC

\section{RESULTS AND DISCUSSIONS}

In the present study the influence of steel fiber variation on Shear strength of RPC have been studied. Different size of L-shape moulds are used for the preparation of samples. Three different percentage of steel fiber (i.e. 1.5, $2.0 \& 2.5 \%$ ) added in the RPC mixture and compare the shear strength of RPC. The variations in the shear strength gained from the different steel fiber variation are tabulated in the table. Experimental results presented in shows that the ultimate single shear strength for RPC with inclusion of fibers increases considerably over its plain RPC. With addition of fiber the specimens do not fail suddenly and the failure load is more than the first crack load. The quantity of fibers used in plain RPC do not significantly affect the first cracking load but a significantly influence on the rate of crack propagation and on the failure load.
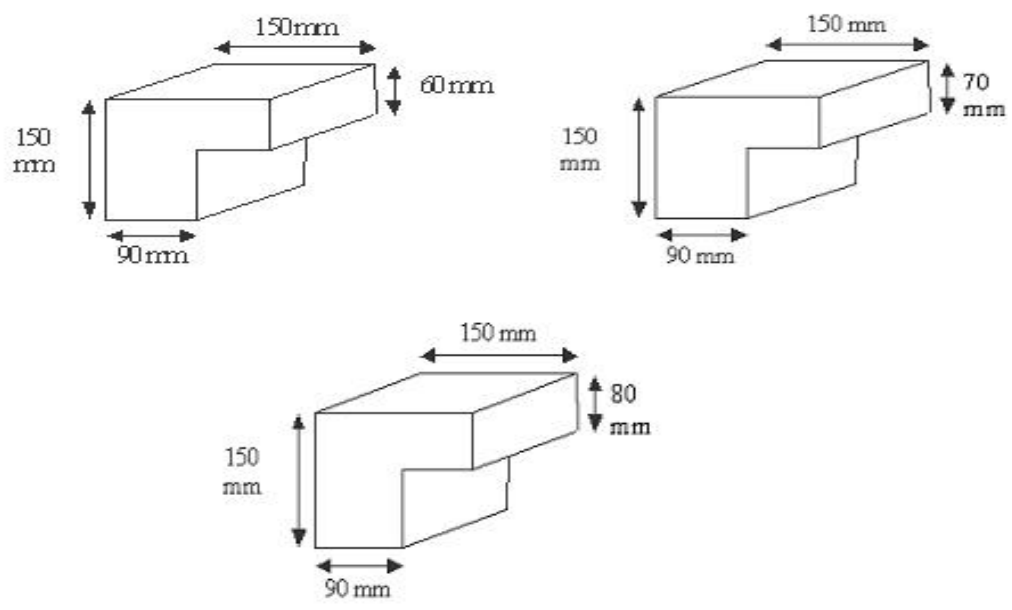
FIG 3.0: L-SHAPED SPECIMENS

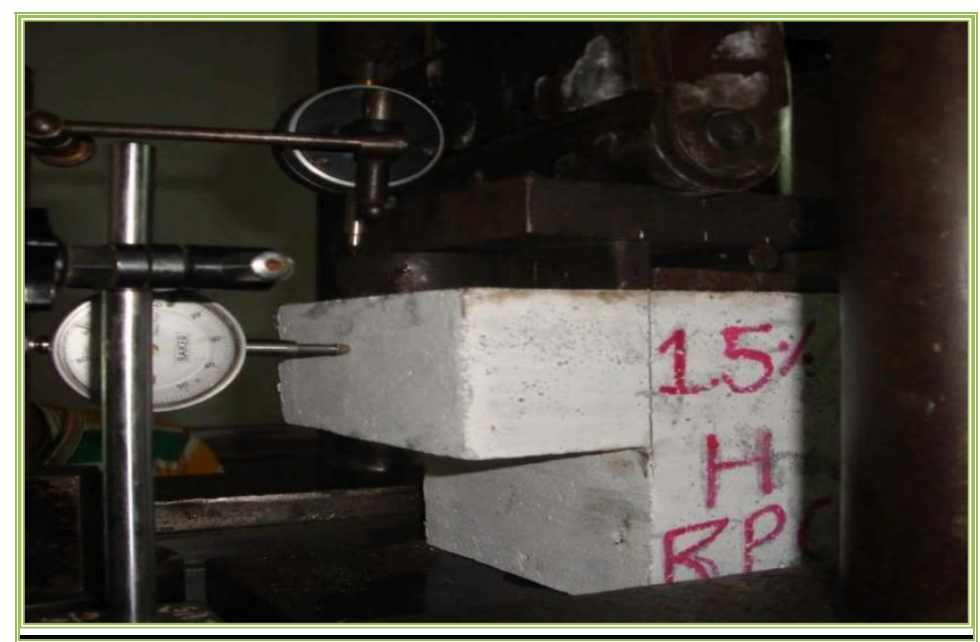

FIG 4.0: PHOTOGRAPH OF EXPERIMENTAL SET-UP FOR SHEAR STRENGTH TEST

Typical shear strength variation with respect to fiber volume fraction and shear plane variations has been plotted in Fig 5 to Fig 7. It can be noted that the maximum increase in shear strength is found for $2 \%$ fiber volume fraction adding in plain RPC. For L shape shear specimen we had observed that optimum shear strength can be obtained for shear plane depth of $70 \mathrm{~mm}$ compared to other depth

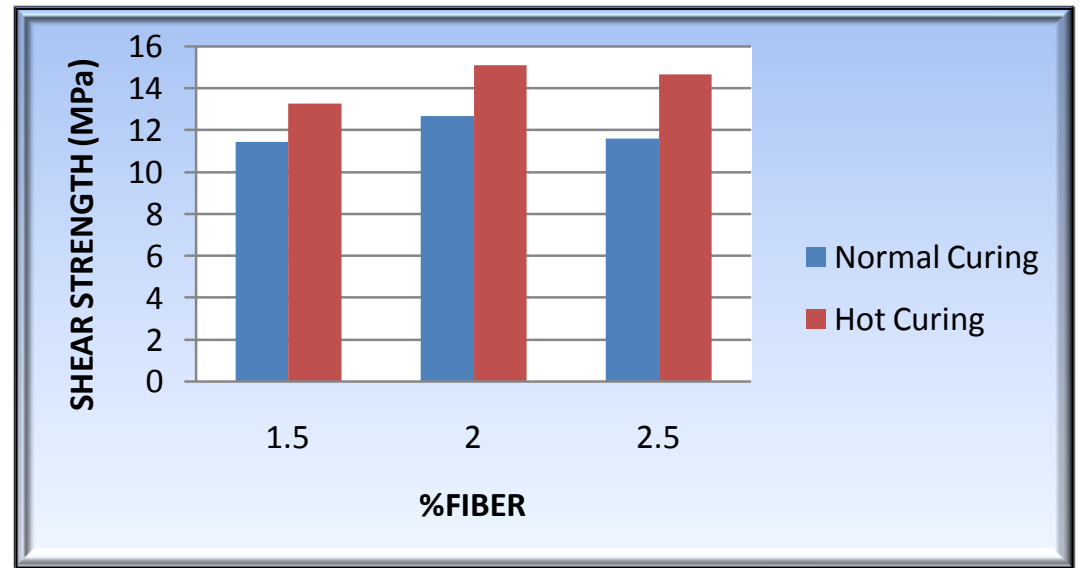

FIG. 5.0: SHEAR STRENGTH OF RPC WITH STEEL FIBERVARIATIONS (SHEAR PLANE 150X60 MM)

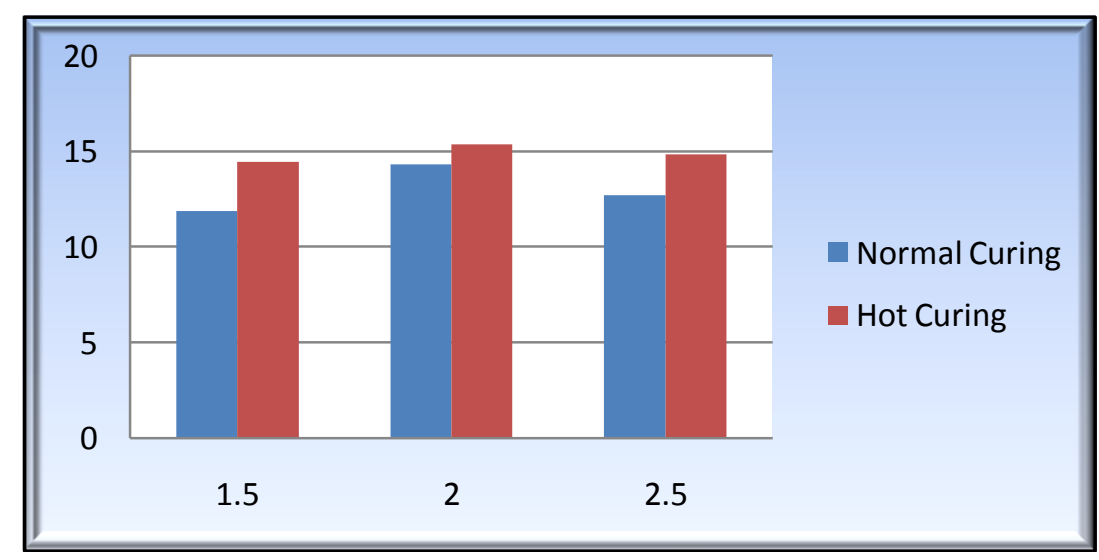

FIG. 6.0: SHEAR STRENGTH OF RPC WITH STEEL FIBER VARIATIONS (SHEAR PLANE 150X70 MM) 


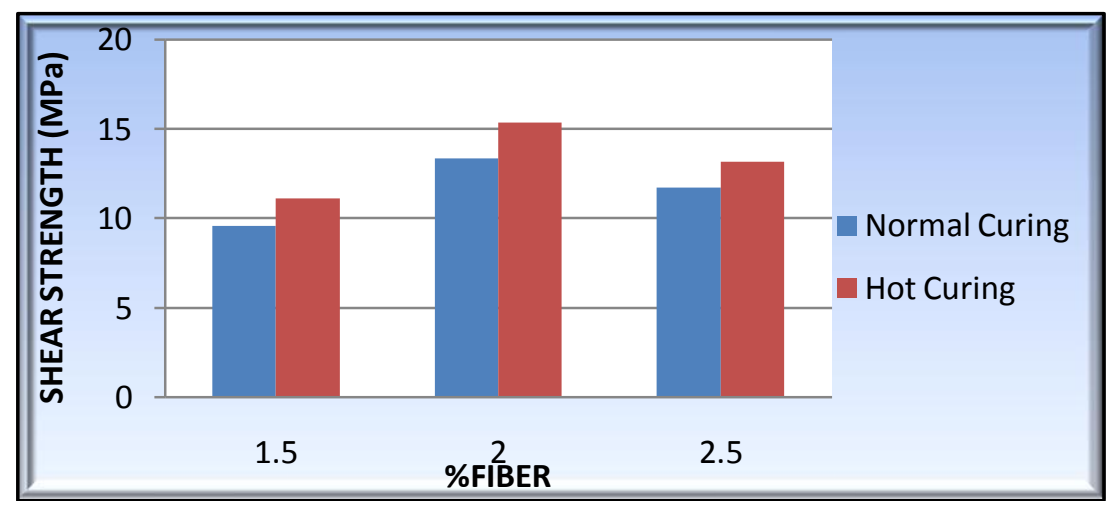

FIG. 7.0: SHEAR STRENGTH OF RPC WITH STEEL FIBER VARIATIONS (SHEAR PLANE 50X80 MM)

\section{CONCLUSIONS}

Results shows that looking at the simplicity of the setup suggested by Bairagi and Modhera, it was also selected here with some modified in loading arrangement for finding the shear strength [46]. This not only resulted in satisfactory failure pattern but also reduced the shear strength and thus provided results more nearer to the JSCE method.

$>$ Due to fiber presence, the brittle shear failure of the cubes is not observed. In fact, the cracks get arrested by fibers and multiple cracks are observed.

$>$ It is clear from the experimental work carried out on inverted L-type of samples that the plain RPC samples failed in a brittle manner at the first crack load which is also the maximum load taken by specimen. On the other hand, samples having $2.5 \%$ fiber indicated multiple visible cracks however $2 \%$ fiber indicates maximum load taken by the samples quite higher than the first crack load, which clearly reflects failure after the strain hardening of the material.

$>$ In $2.5 \%$ fiber volume fraction inverted L-type of samples multiple cracks were observed but the shear strength was found less than the $2 \%$ fiber samples. Thus, $2 \%$ fiber volume content can be considered as optimum fiber content required for getting optimum properties of RPC in shear.

$>$ It is clear from the experimental work carried out on inverted L- type of samples that high shear strength achieved by increasing thickness of cantilever portion. Therefore, thickness is varying up to 60 to $75 \mathrm{~mm}$ that gives optimum shear stress.

$>$ shear strength increases for shear plane width $70 \mathrm{~mm}$ than shear plan width $60 \mathrm{~mm}$. and decreases for shear plane width $80 \mathrm{~mm}$ than shear plan width $70 \mathrm{~mm}$. so, we can say that we get optimum shear strength for shear plane width $70 \mathrm{~mm}$ than shear plane width $60 \mathrm{~mm}$ and $80 \mathrm{~mm}$. Optimum shear value can be obtained in a width of shear plane to be 60 to $75 \mathrm{~mm}$.

\section{REFERENCES}

[1] A. S. Dili and Manu Santhanam (2004) "Investigation on Reactive Powder Concrete: A Developing Ultra HighStrength Technology" Indian Concrete Journal.

[2] Abdeldjelil and Thomas T.C.Hsu (1995) "Constitutive Laws of Softened in Biaxial Tension-Compression” ACI Structural Journal, Vol 92 No.[5]

[3] Abouzar Sadrekarimi. (2004) "Development Of A Light Weight Reactive Powder Concrete”. Journal Of Advanced Concrete Technology Vol. 2, no. 3, 409-417.

[4] Aicha Kamen, Emmanuel Denarie And Eugen Bruhwiler. (2007) "Thermal Effects On Physico-Mechanical Properties Of Ultra-High-Performance Fiber-Reinforced Concrete", ACI Material Journal.

[5] Ali R. Khaloo and Nakseok kim. (1997) "Influence Of Concrete And Fiber Characteristics On Behaviour Of Steel Fiber Reinforced Concrete Under Direct Shear" ACI Structural Journal, Vol. 94 No.[6].

[6] Ammar Hassan And Makoto Kawakami (2005) "Steel Free Composite Slabs Made Of Reactive Powder Materials And Fiber Reinforced Concrete, ACI Structural Journal, Vol. 102 No. [5].

[7] Arnaud Poitou, Francisco Chinesta, And Ge'Rard Bernier. "Orienting Fibers by Extrusion In Reinforced Reactive Powder Concrete".

[8] ASTM International Standard Test Method for Compressive Strength of Hydraulic Cement Mortars, (using [50-mm] cube specimens), C-109/c 109m-05, C-109-99.

[9] ASTM International Standard Test Method for Flow Of Hydraulic Cement Mortar, C-1437-01,

[10] B.I.G.BARR and K.L.W.LIU (1983) “A compact test specimen” Journal Of Materials Science Letters 2663-664.

[11] Bairagi N. K. and Modhera C.D. (2001) "Shear Strength of Fibre Reinforced Concrete" ICI Journal Vol 1 No.[4].

[12] Bairagi, n. K. \& Modhera, C. D. (2004) "An Experimental Study Of Shear Strength Test Method For SFRC”, Proceedings Of International Conference On Advances In Concrete And Construction, Vol. No. 1. 